\title{
Effects of herbal nutraceuticals and/or zinc against Haemonchus contortus in lambs experimentally infected
}

Zora Váradyová', Dominika Mravčáková1, Michal Babják², Magdalena Bryszak³, L’ubomíra Grešáková1, Klaudia Čobanová', Svetlana Kišidayová', Iveta Plachá , Alžbeta Königová2, Adam Cieslak , Sylwester Slusarczyk ${ }^{4,5}$, Lukasz Pecio ${ }^{4}$, Mariusz Kowalczyk ${ }^{4}$ and Marián Várady ${ }^{2^{*}}$ (I)

\begin{abstract}
Background: The gastrointestinal parasitic nematode Haemonchus contortus is a pathogenic organism resistant to several anthelmintics. This study assessed the efficacy of a medicinal herbal mixture (Herbmix) and organic zinc, as an essential trace element for the proper functioning of both unspecific and specific immune defensive mechanisms, against experimental infections with $\mathrm{H}$. contortus in lambs. All lambs were infected orally with approximately 5000 thirdstage larvae of a strain of $\mathrm{H}$. contortus susceptible to anthelmintics (MHco 1). Twenty-four female lambs 3-4 months of age were divided into four groups: unsupplemented animals (control), animals supplemented with Herbmix (Hmix), animals supplemented with organic zinc (Zn) and animals supplemented with Herbmix and organic zinc (Hmix $+\mathrm{Zn}$ ). Eggs per gram (EPG) of faeces were quantified 20, 28, 35, 42, 49, 56, 62 and 70 d post-infection and mean abomasal worm counts were assessed $70 \mathrm{~d}$ post-infection. Samples of blood were collected from each animal 7, 35, 49 and $70 \mathrm{~d}$ post-infection.
\end{abstract}

Results: Quantitative analyses of the bioactive compounds in Herbmix identified three main groups: flavonoids (9964. $7 \mu \mathrm{g} / \mathrm{g}$ ), diterpenes $(4886.1 \mu \mathrm{g} / \mathrm{g}$ ) and phenolic acids (3549.2 $\mu \mathrm{g} / \mathrm{g})$. Egg counts in the lambs treated with Hmix, Zn and Hmix $+Z n$ decreased after $49 \mathrm{~d}$. The EPGs in the Zn and Hmix+Zn groups were significantly lower on day 56 $(P<0.05$ and $P<0.01$, respectively), and the EPGs and mean worm counts were significantly lower on day 70 in all supplemented groups $(P<0.05$ and $P<0.01)$. Hemograms of complete red blood cells of each animal identified clinical signs of haemonchosis after day 35. Serum calprotectin concentrations and IgA levels were significantly affected by treatment. The treatment influenced serum malondialdehyde concentrations $(P<0.05)$ and sulfhydryl groups $(P<0.01)$ of antioxidant status. The mineral status was unaltered in all lambs.

Conclusion: A direct anthelmintic impact on the viability of nematodes was not fully demonstrated, but the treatments with herbal nutraceuticals and zinc likely indirectly contributed to the increase in the resistance of the lambs to nematode infection.

Keywords: Anthelmintic activity, Egg counts, Gastrointestinal nematode, Haemonchus contortus, Herbal bioactive compounds, Mineral status, Organic zinc, Sheep

\footnotetext{
* Correspondence: varady@saske.sk

${ }^{2}$ Institute of Parasitology, Slovak Academy of Sciences, Hlinkova 3, 04001

Košice, Slovak Republic

Full list of author information is available at the end of the article
} International License (http://creativecommons.org/licenses/by/4.0/), which permits unrestricted use, distribution, and reproduction in any medium, provided you give appropriate credit to the original author(s) and the source, provide a link to the Creative Commons license, and indicate if changes were made. The Creative Commons Public Domain Dedication waiver (http://creativecommons.org/publicdomain/zero/1.0/) applies to the data made available in this article, unless otherwise stated. 


\section{Background}

Plant secondary metabolites (PSMs) of medicinal herbs, which have been used for centuries in traditional medicine and veterinary practice to treat various digestive or parasitic disorders, have important biological activities [1-3]. PSMs are bioactive compounds with applications in nutraceuticals and functional food. Compounds with nutraceutical activity $[4,5]$ however, are mostly produced chemically, but new demands for a sustainable life are gradually favoring natural compounds, mainly those derived from herbs [6]. A recent study [7] has summarized information from 2001 to 2016 on polyphenols demonstrating promising anthelmintic activities of polyphenols that can be used as an additional or alternative treatment to current standard anthelmintics and as a base for the development of new substances that are urgently needed in human and veterinary medicine.

Chemoprophylaxis against the gastrointestinal parasitic nematode Haemonchus contortus by the repeated application of anthelmintics increases the risk of residues in food products and the development of anthelmintic resistance. Studies of foods containing healthy additives and having medicinal benefits in parasitized ruminants indicate that herbs with bioactive compounds represent a promising option for reducing nematode infections in small ruminants and for applications under farm conditions [8-10]. Phytotherapeutic treatments in traditional medicine [11] combined with the pharmacology of PSMs [12] and self-medication of ruminants against gastrointestinal parasites [13] can be used as an alternative strategy to control gastrointestinal helminths of small ruminants. The ability of the host to resist infection by gastrointestinal nematodes, though, is dependent on the development of a protective acquired immune response [14]. Nematode infections may also induce the production of reactive oxygen species, which may damage the parasites but generate oxidative stress in the hosts [15]. The trace element zinc is essential for the proper functioning of both unspecific and specific immune defensive mechanisms and reduces the impact of many diseases by preventing disassembly of the immune system $[16,17]$. Zinc is essential for the improvement of the immune functions because the efficiency of immunological responses, mainly intestinal immunity, against gastrointestinal nematodes depends on the zinc status and $\mathrm{Zn}$ nutrition [17]. The type of diet and availability of minerals are directly associated with the susceptibility of animals to parasites. Targeted nutrition and in vitro protocols for the mass production of PSMs have received much attention, but little emphasis has been placed on nutraceutical activity and analysis [6]. Supplementing diets with both medicinal herbs and zinc has therefore been hypothesized to affect the life cycle of $H$. contortus, have a direct anthelmintic impact on the viability of nematodes and may provide a better defense against oxidative stress of lambs, with an indirect impact on an increase in the resistance of hosts to parasitic infections of $H$. contortus. In this study the mix of traditional medicinal herbs (Herbmix) consist of herbs typical for Central Europe. These herbs were chosen based on information about their phytotherapeutic properties from traditional ethnomedicine practice.

Our goals were to (1) identify the main bioactive compounds of a medicinal herbal mixture (Herbmix) and (2) determine the effect of dietary supplementation with Herbmix and organic zinc (Zn-glycinate) on mean live-weight gain, parasitological status, hematological parameters, inflammatory response, antioxidative status and mineral status of lambs experimentally infected with $H$. contortus.

\section{Methods}

Animals, diets and experimental design

Twenty-four female lambs (Improved Valachian) 34 months of age with initial body weights of $15.12 \pm$ $1.58 \mathrm{~kg}$ were housed in common stalls for $7 \mathrm{~d}$ for acclimatization to feeding, with free access to water. Each animal was fed a concentrate (500 g dry matter $(\mathrm{DM}) / \mathrm{d}$ ), Herbmix (a non-commercial product, $100 \mathrm{~g}$ $\mathrm{DM} / \mathrm{d}$ ) and meadow hay (ad libitum). The concentrate was composed of $37 \%$ wheat bran, $20 \%$ soybean meal, $23 \%$ rolled oats and 20\% maize meal. After this adaptation period, all parasite free lambs were separated into four distinct pens, infected orally with approximately 5000 third-stage (L3) larvae of a strain of $H$. contortus susceptible to anthelmintics MHcol (MOSI) which is susceptible to all the main classes of anthelmintics. It has been maintained since the late 1950s, and is thought to have been isolated in East Africa. Animals were randomly divided based on their live-weight into four groups of six animals each $(n=6 /$ group, one stall per group): unsupplemented animals (control, C), animals supplemented with Herbmix (Hmix), animals supplemented with a zinc chelate of glycine hydrate Glycinoplex-Zn 26\% (Zn) and animals supplemented with both Herbmix and zinc $(\mathrm{Hmix}+\mathrm{Zn})$. The number of animals used in experiment was assigned according to VICH GL13 guidelines. The experimental period lasted 70 days (during summer) and the animals were housed in sheep farm. Herbmix is a mixture of dry herbs obtained from commercial sources (AGROKARPATY, Plavnica, Slovak Republic and BYLINY Mikeš s.r.o., Č́ičenice, Czech Republic): roots of marshmallow (Althaea officinalis L.), butterbur (Petasites hybridus L.) and elecampane (Inula helenium L.); leaves of ribwort plantain (Plantago lanceolata L.) and rosemary (Rosmarinus officinalis L.); seeds of fennel (Foeniculum vulgare Mill.) and stems of goldenrod (Solidago virgaurea L.), fumitory (Fumaria officinalis L.) and hyssop (Hyssopus officinalis L.). The Herbmix contained $11.8 \%$ each of $A$. 
officinalis, P. hybridus, I. helenium, P. lanceolata, $R$. officinalis, $S$. virgaurea, $F$. officinalis and $H$. officinalis and $5.6 \% F$. vulgare. The Herbmix was stable throughout the experiment, mixed daily with the commercial concentrate from day D7 to D70. Aliquots of the zinc supplement were directly mixed with the concentrate for each feeding to provide an additional $60 \mathrm{mg}$ zinc $/ \mathrm{kg}$ concentrate. The allowed upper limits of zinc in complete feed is $120 \mathrm{mg} / \mathrm{kg}$ for food-producing animals [18]. Herbal and zinc supplementation began on D7. The chemical compositions of Herbmix, meadow hay, commercial concentrate and concentrate + Glycinoplex$\mathrm{Zn}$ are given in Table 1. The lambs' wool was clipped on D3. The lambs were weighed on D7, D35, D49 and D70. Faeces were collected from the rectum, and the number of eggs per gram (EPG) of faeces was quantified on D0, D20, D28, D35, D42, D49, D56, D62 and D70. Samples of blood were collected from each animal on D7, D35, D49 and D70.

\section{Chemical measurement and analysis}

The dietary substrates (Herbmix, meadow hay, concentrate and concentrate $+\mathrm{Zn}$-glycinate) were analyzed in triplicate for DM (No. 967.03), ash (method no. 942.05) nitrogen (method no. 968.06) and crude protein (method no. 990.03) using standard methods as described by AOAC [19]. The acidic-detergent fiber and neutraldetergent fiber contents were analyzed as described by Van Soest et al. [20] using an ANKOM 2000 fiber analyzer (ANKOM Technology, Macedon, USA) with heat-stable $\alpha$-amylase.

\section{Analysis of phenolic acids, flavonoids and diterpenes}

The plant samples were ground to a fine powder, and $100 \mathrm{mg}$ were extracted three times with a Dionex ASE (Accelerated Solvent Extractor, ThermoFisher, Sunnyvale, CA, USA) in $80 \% \mathrm{MeOH}$ for 15 min (three static cycles, 5 min each), at 1500 psi solvent pressure, $100{ }^{\circ} \mathrm{C}$ cell temp., flush $150 \%$. The extracts were evaporated to dryness, dissolved in $1 \mathrm{~mL}$ of Milli-Q water (acidified with $0.2 \%$ formic acid) and purified by Solid Phase Extraction (SPE) using C18 Sep-Pak cartridges $\left(1 \mathrm{~cm}^{3}\right.$, 360 mg, Waters Corp., Milford, MA). The cartridges were washed with $0.5 \%$ methanol to remove carbohydrates, and then washed with $80 \%$ methanol to elute phenolics. The phenolic fraction was evaporated and dissolved in $1 \mathrm{~mL}$ of $80 \%$ methanol (acidified with $0.2 \%$ formic acid). The sample (intense yellow color without chlorophyll) was than centrifuged $(18,766 \times g, 5 \mathrm{~min})$ before spectrometric analysis. All analyses were performed in triplicate for three independent samples and stored in a freezer at $-20{ }^{\circ} \mathrm{C}$ before analysis.

\section{Ultra-high-resolution mass spectrometry (UHRMS)}

The Herbmix bioactive compounds were analyzed by UHRMS on a Dionex UltiMate 3000RS (Thermo Scientific, Darmstadt, Germany) system with a charged aerosol detector interfaced with a high-resolution quadrupole time-of-flight mass spectrometer (HR/Q-TOF/MS, Impact II, Bruker Daltonik GmbH, Bremen, Germany). The Herbmix metabolome was chromatographically separated on an Acquity UPLC BEH C18 column $(100 \times 2.1 \mathrm{~mm}$, $1.7 \mu \mathrm{m}$, Waters, Manchester, UK) maintained at $50{ }^{\circ} \mathrm{C}$. The mobile phase consisted of: A $(0.1 \%$ formic acid in Milli-Q water, $v / v)$ and B $(0.1 \%$ formic acid in acetonitrile, $\mathrm{v} / \mathrm{v})$ at a flow rate of $0.4 \mathrm{~mL} / \mathrm{min}$. The gradient elution was: $7 \% \mathrm{~B}$ from 0 to $0.5 \mathrm{~min}$ with a short $0.3 \mathrm{~min}$ calibration segment, and the concentration of $\mathrm{B}$ was then increased to $70 \%$ from 0.5 to $17 \mathrm{~min}$. The column was eluted with this concentration of solvent B for $0.5 \mathrm{~min}$ and was then re-equilibrated for $0.2 \mathrm{~min}$ at a flow rate of $0.5 \mathrm{~mL} / \mathrm{min}$ at $50{ }^{\circ} \mathrm{C}$. The samples were kept at $15{ }^{\circ} \mathrm{C}$ in the autosampler. The injection volume was $5.0 \mu \mathrm{L}$. The mass spectrometer was operated in the positive atmospheric-pressure chemical ionization (APCI) mode after confirmation of low sensitivity and poor resolution in the negative mode. An APCI tuning mix (Agilent, Santa Clara, CA, USA) (Pos) in quadratic mode and locked mass was used for calibration with the following parameters: capillary voltage was set at $2.8 \mathrm{kV}$, nebulizer $0.7 \mathrm{bar}$, dry gas $6.0 \mathrm{~L} / \mathrm{min}$ and dry temperature $200{ }^{\circ} \mathrm{C}$. The mass scan range was set at 50-1870 m/z. MS/MS spectra were acquired in a data-dependent manner, whereby ions (maximum 2) from each scan were subjected to collisioninduced fragmentation if their absolute intensity exceeded 1800 counts. The variable collision energy ranged from 15

Table 1 Chemical composition of the diet substrates and main Herbmix phytochemicals

\begin{tabular}{|c|c|c|c|c|c|c|c|c|c|c|}
\hline \multirow[t]{2}{*}{ Substrate } & DM & NDF & ADF & $\mathrm{CP}$ & $\mathrm{N}$ & Ash & Zinc & $\begin{array}{l}\text { Phenolic } \\
\text { acids }\end{array}$ & Diterpenes & Flavonoids \\
\hline & $(\mathrm{g} / \mathrm{kg})$ & (g/kg DM) & (g/kg DM) & (g/kg DM) & (g/kg DM) & (g/kg DM) & $(\mathrm{mg} / \mathrm{kg})$ & $(\mathrm{mg} / \mathrm{g} D M)$ & (mg/g DM) & $(\mathrm{mg} / \mathrm{g} \mathrm{DM})$ \\
\hline Herbmix & 905 & 532 & 452 & 207 & 33 & 84 & 26.2 & 3.55 & 4.89 & 9.96 \\
\hline Meadow hay & 900 & 651 & 556 & 163 & 27 & 91 & 66.3 & n.d. & n.d. & n.d. \\
\hline Concentrate & 878 & 136 & 83 & 309 & 49 & 29 & 41.1 & n.d. & n.d. & n.d. \\
\hline $\begin{array}{l}\text { Concentrate } \\
+ \text { zinc }\end{array}$ & 876 & 254 & 93 & 352 & 56 & 30 & 88.8 & n.d. & n.d. & n.d. \\
\hline
\end{tabular}

$D M$ dry matter, NDF neutral-detergent fiber, $A D F$ acid-detergent fiber, $C P$ crude protein, $N$ nitrogen, Ash mineral matter present in feed, $n . d$. not determined 
to $35 \mathrm{eV}$ depending on the ion's $\mathrm{m} / \mathrm{z}$. Internal calibration used an APCI-TOF (pos) tuning mix introduced to the ion source via a $20-\mu \mathrm{L}$ loop at the beginning/end of each analysis using a six-port valve. Data were collected and processed by DataAnalysis 4.3 (Bruker Daltonik GmbH, Bremen, Germany). Stock solutions of quercetrin (quercetin 3-rhamnoside), rosmarinic acid and cryptotanshinone were prepared in $\mathrm{MeOH}$ at concentrations of 4.2, 5.6 and $4.1 \mathrm{mg} / \mathrm{mL}$, respectively, and kept frozen until used. Calibration curves for these three compounds were constructed based on six concentration points (from $500 \mathrm{ng} / \mathrm{mL}$ to $6 \mu \mathrm{g} / \mathrm{mL}$ ). The concentrations of the phenolic derivatives in the Herbmix sample were calculated as equivalents of quercetrin (quercetin 3-rhamnoside) or rosmarinic acid, and cryptotanshinone was used to calculate the amount of diterpenoids identified in the extract. All analyses were performed in triplicate.

\section{Parasitological techniques}

Fecal samples were collected on D20, D28, D35, D42, D49, D56, D62 and D70 post-infection and stored at $5{ }^{\circ} \mathrm{C}$ in a cooling box until laboratory examination. A modified McMaster technique [21] with a sensitivity of 50 EPG of faeces was used for the detection of strongylid eggs. All animals were humanely killed on D70 and postmortem helminthological dissections were performed. The abomasum was removed and opened, and the contents were emptied into a bucket. The abomasal mucosa was washed gently with water, washing the parasites into the bucket. The contents of the bucket were adjusted to two liters and thoroughly mixed. Two aliquots of $100 \mathrm{~mL}$ were then taken, and the numbers of $H$. contortus in each aliquot were counted.

\section{Hematological parameters}

Samples of blood were collected from the jugular vein of each animal on D7, D35, D49 and D70 using a 21-gauge needle and syringe and were placed into microtubes containing $1.6 \mathrm{mg} / \mathrm{mL}$ EDTA-K3 (Sarstedt AG \& Co, Nümbrecht, Germany). Hematological parameters (red blood cells, hemoglobin, hematocrit, total leukocytes, lymphocytes, monocytes, eosinophils and basophils) were determined immediately by an automated hematological analyzer (Abbott CELL-DYN 3700, Global Medical Instrumentation, Inc., Ramsey, USA). Blood samples for sera were collected into 10-mL serum-separator tubes (Sarstedt AG \& Co, Nümbrecht, Germany) and centrifuged at $1200 \mathrm{~g}$ for $10 \mathrm{~min}$ at room temperature. The sera were stored at $-80^{\circ} \mathrm{C}$ until analysis.

\section{Inflammatory response}

The concentrations of serum amyloid A (SAA) and serum calprotectin were determined using commercial sheep ELISA kits (MyBioSource Ltd., San Diego, USA).
Undiluted serum samples were analyzed following the manufacturer's instructions. The SAA and calprotectin concentrations had coefficients of variation $<10$ and $<$ $15 \%$ (intra- and interassay), respectively. The sensitivities of the Elisa kits were $0.1 \mathrm{ng} / \mathrm{mL}$ for calprotectin and $0.1 \mu \mathrm{g} / \mathrm{mL}$ for SAA. The detection range of the SAA kit was $3.12-100 \mu \mathrm{g} / \mathrm{mL}$. All samples were analyzed in duplicate. The optical density of the samples was determined at $450 \mathrm{~nm}$ using an Apollo 11 LB913 Elisa absorbance reader (Berthold Technologies GmbH \& Co. KG, Bad Wildbad, Germany). We analyzed both parameters on D7, D35 and D49. Serum immunoglobulin A (IgA) was measured with a sheep IgA enzyme-linked immunosorbent assay (Sheep Immunoglobulin A ELISA Kit, Cusabio, Wuhan Huamei Biotech Co., LTD, Wuhan, China). The sensitivity of the kit was $1.87 \mu \mathrm{g} / \mathrm{mL}$. A HydroSpeed microplate washer (Tecan Austria GmbH, Grödig/Salzburg, Austria) was used for improving assay precision. The IgA values were determined on D7, D35, D49 and D70 using a microplate reader, with the same optical density described above.

\section{Antioxidant status}

The total antioxidant capacity (TAC) of the serum was measured by an assay for ferric reducing antioxidant power described by Benzie and Strain [22]. A ferrous sulfate solution was used to create a standard curve, and the results were expressed in $\mathrm{mmol} \mathrm{Fe}{ }^{2+}$ formed per liter of sample. The activity of glutathione peroxidase (GPx) in the blood was assessed spectrophotometrically as described by Paglia and Valentine [23] using a Ransel kit (Randox Laboratories, Ltd., London, UK). The enzymatic activity was evaluated at $37{ }^{\circ} \mathrm{C}$ at a wavelength of $340 \mathrm{~nm}$, and the results are expressed in units per $\mathrm{mL}$ of blood. The extent of lipid peroxidation indicated by malondialdehyde (MDA) level using 1, 1, 3, 3-teramethoxypropane (Sigma-Aldrich) as an MDA precursor in the calibration curve was determined following the method of Jo and Ahn [24]. Serum total thiol or sulfhydryl (SH) concentration was determined spectrophotometrically using Ellman's method, based on the reaction of 5,5'-dithio-bis (2-nitrobenzoic acid) with protein thiol groups measured at $412 \mathrm{~nm}$ [25]. The concentration of SH groups was calculated using reduced glutathione as the standard, and the results are expressed in $\mathrm{mmol} / \mathrm{L}$.

\section{Mineral status}

The mineral content in the diet substrates and the serum concentrations of zinc, iron and copper in the lambs were determined by flame atomic absorption spectrometry in an air-acetylene flame, with deuterium background correction [26], using an AA-7000 atomic absorption spectrophotometer (Shimadzu Co., Kyoto, Japan). Certified lyophilized human plasma, ClinCheck 
Control (Recipe, Munich, Germany), was used to determine the precision of the analysis.

\section{Calculations and statistical analysis}

Calprotectin, SAA and IgA concentrations were calculated by a four-parameter logistic curve fit (GraphPad Prism, GraphPad Software, Inc., San Diego, USA). Analyses of variance (ANOVAs) (GraphPad Prism, GraphPad Software, Inc., San Diego, USA) were used for analyzing initial body weights (BWs), live-weight gains (LWGs), hematological parameters, inflammatory response, antioxidant status and mineral status as repeated-measures mixed models representing the four animal groups (Control, Herbmix, $\mathrm{Zn}$ and Herbmix $+\mathrm{Zn})$ and sampling days. Effects included in the model were treatment, time and the interaction between treatment and time. Student's $t$-tests were applied to assess the differences between mean egg outputs (EPGs) on different sampling days and worm counts at dissection (Fig. 2, Fig. 3). Results were considered statistically significant at $P<0.05$.

\section{Results}

Bioactive compounds

Quantitative analyses of the bioactive compounds in Herbmix (Table 2) identified three main groups: flavonoids $(9964.7 \mu \mathrm{g} / \mathrm{g})$, diterpenes $(4886.1 \mu \mathrm{g} / \mathrm{g})$ and phenolic acids $(3549.2 \mu \mathrm{g} / \mathrm{g})$. Phenolic acids are Nos. 1 and 12; flavonoids are Nos. 2, 3, 4, 5, 6, 7, 8, 9, 10, 11, 13, 14, 15, 16 and 19 and diterpenes are Nos. 17, 18, 20, 21, 22, 23, 24 and 25. Peak numbers in Fig. 1 represent the main compounds as numbered in Table 2.

\section{Parasitological status}

All lambs had similar BWs (Table 3). Time $(P<0.001)$ affected BW and the mean cumulative LWG. The patterns of shedding of eggs in $\mathrm{C}, \mathrm{Hmix}, \mathrm{Zn}$ and $\mathrm{Hmix}+\mathrm{Zn}$ are shown in Fig. 2. Data from D49 were used to determine the reduction in egg output in Hmix, $\mathrm{Zn}$ and Hmix $+\mathrm{Zn}$ relative to $C$. The mean fecal egg count for all groups increased until D49, with no significant differences between groups $(P>0.05)$, but the egg counts in the lambs treated with Herbmix, zinc and a combination of both decreased

Table 2 Contents of the main bioactive compounds identified in Herbmix analyzed in positive and negative ionization modes

\begin{tabular}{|c|c|c|c|c|c|c|c|c|c|}
\hline No. & Compound & $\mathrm{RT}$ (min) & UV & $m / z[M-H]^{-}$ & Formula & MS fragment & $m / z[\mathrm{M}+\mathrm{H}]^{+}$ & MS fragment & $\mu \mathrm{g} / \mathrm{g} D \mathrm{DM}$ \\
\hline 1 & Chlorogenic acid & 2.05 & $215 / 325$ & 353.0880 & $\mathrm{C}_{16} \mathrm{H}_{18} \mathrm{O}_{9}$ & 191 & 355.1015 & 163 & 663.1 \\
\hline 2 & Quercetin-O-Hex-Hex & 3.33 & 200/335 & 625.1419 & $\mathrm{C}_{27} \mathrm{H}_{30} \mathrm{O}_{17}$ & 301 & 627.1545 & $303 / 465 / 161$ & 134.5 \\
\hline 3 & Hypolaetin-O-Hex & 3.50 & $255 / 345$ & 463.0890 & $\mathrm{C}_{21} \mathrm{H}_{20} \mathrm{O}_{12}$ & 301 & 465.1016 & 303 & 298.5 \\
\hline 4 & Luteolin 7-glucuronide & 3.84 & 220/255/345 & 461.0730 & $\mathrm{C}_{21} \mathrm{H}_{18} \mathrm{O}_{12}$ & $285 / 163$ & 463.0865 & $287 / 257$ & 422.2 \\
\hline 5 & Quercetin-O-Hex & 3.95 & $265 / 340$ & 463.0890 & $\mathrm{C}_{21} \mathrm{H}_{20} \mathrm{O}_{12}$ & 301 & 465.1018 & $303 / 382 / 141$ & 573.1 \\
\hline 6 & Quercetin-O-Hex-Pent & 4.05 & $220 / 350$ & 595.1309 & $\mathrm{C}_{26} \mathrm{H}_{28} \mathrm{O}_{16}$ & 301 & 597.1437 & $303 / 465$ & 430.9 \\
\hline 7 & Quercetin-O-Hex-dHex & 4.2 & 220/255/345 & 609.1466 & $\mathrm{C}_{27} \mathrm{H}_{30} \mathrm{O}_{16}$ & 301 & 611.1599 & $303 / 465$ & 1436.7 \\
\hline 8 & Verbascoside & 4.340 & $195 / 330$ & 623.1985 & $\mathrm{C}_{29} \mathrm{H}_{36} \mathrm{O}_{15}$ & $461 / 315 / 161$ & 625.1756 & $471 / 325 / 163$ & 1162.9 \\
\hline 9 & 3,5-Dicaffeoyl-quinic acid & 4.450 & $200 / 325$ & 515.1198 & $\mathrm{C}_{25} \mathrm{H}_{24} \mathrm{O}_{12}$ & $191 / 353$ & 517.1339 & $163 / 319$ & 1602.6 \\
\hline 10 & Quercetin-O-dHex-dHex & 4.553 & $260 / 345$ & 593.1512 & $\mathrm{C}_{27} \mathrm{H}_{30} \mathrm{O}_{15}$ & - & 595.1645 & $303 / 449$ & 1441.1 \\
\hline 11 & Luteolin-glucuronide & 4.951 & $210 / 340$ & 461.0726 & $\mathrm{C}_{21} \mathrm{H}_{18} \mathrm{O}_{12}$ & 285 & 463.0868 & $287 / 299$ & 1058.0 \\
\hline 12 & Rosmarinic acid & 4.955 & $200 / 330$ & 359.0770 & $\mathrm{C}_{18} \mathrm{H}_{16} \mathrm{O}_{8}$ & 161/197/179 & 361.0912 & $163 / 181$ & 2886.1 \\
\hline 13 & Luteolin 3'-(3"-acetylglucuronide) & 5.620 & $270 / 335$ & 503.0831 & $\mathrm{C}_{23} \mathrm{H}_{20} \mathrm{O}_{13}$ & $285 / 255$ & 505.0976 & 287 & 296.9 \\
\hline 14 & Luteolin 3'-(4"-acetylglucuronide) & 5.740 & $270 / 335$ & 503.0834 & $\mathrm{C}_{23} \mathrm{H}_{20} \mathrm{O}_{13}$ & 285 & 505.0977 & 287 & 521.7 \\
\hline 15 & Luteolin-(malonyl-Pent) & 6.190 & $270 / 335$ & 503.0833 & $\mathrm{C}_{23} \mathrm{H}_{20} \mathrm{O}_{13}$ & 285 & 505.0978 & 287 & 352.7 \\
\hline 16 & Isomargaritene & 6.425 & $270 / 330$ & 591.1709 & $\mathrm{C}_{28} \mathrm{H}_{32} \mathrm{O}_{14}$ & 283/268/163 & 593.1862 & $285 / 447$ & 221.6 \\
\hline 17 & Rosmanol & 8.5 & $275 / 330$ & 345.1704 & $\mathrm{C}_{20} \mathrm{H}_{26} \mathrm{O}_{5}$ & $301 / 283$ & 347.1845 & $301 / 283 / 273 / 231$ & 612.7 \\
\hline 18 & Isorasmanol or Royleanonic acid & 9.05 & $220 / 335$ & 345.1705 & $\mathrm{C}_{20} \mathrm{H}_{26} \mathrm{O}_{5}$ & $283 / 268 / 227$ & 347.1846 & $301 / 273 / 259$ & 34.1 \\
\hline 19 & Acacetin & 9.68 & $220 / 340$ & 283.0611 & $\mathrm{C}_{16} \mathrm{H}_{12} \mathrm{O}_{5}$ & 268 & 285.0752 & - & 11.3 \\
\hline 20 & Royleanonic acid-derivative & 10.7 & - & 345.1710 & $\mathrm{C}_{20} \mathrm{H}_{26} \mathrm{O}_{5}$ & $283 / 268 / 227$ & 347.1848 & $301 / 273 / 259$ & 296.8 \\
\hline 21 & Carnosol derivative & 11.25 & - & 329.1753 & $\mathrm{C}_{20} \mathrm{H}_{26} \mathrm{O}_{4}$ & 285 & 331.1901 & 285/267/303/243 & 96.1 \\
\hline 22 & Komaroviquinone & 12.3 & 220 & 359.1859 & $\mathrm{C}_{21} \mathrm{H}_{28} \mathrm{O}_{5}$ & - & 361.2012 & 299/233 & 1127.1 \\
\hline 23 & Carnosol & 12.5 & 205 & 329.1754 & $\mathrm{C}_{20} \mathrm{H}_{26} \mathrm{O}_{4}$ & 285 & 331.1899 & 285/267/303/243 & 1356.6 \\
\hline 24 & Carnosic acid & 14.6 & 225 & 331.1908 & $\mathrm{C}_{20} \mathrm{H}_{28} \mathrm{O}_{4}$ & $287 / 245$ & 333.2048 & $287 / 245$ & 651.5 \\
\hline 25 & $\begin{array}{l}\text { 12-Hydroxy-11-methoxy-8,11, } \\
\text { 13-abietatrien-20-oic acid }\end{array}$ & 15.3 & 230 & 345.2066 & $\mathrm{C}_{21} \mathrm{H}_{30} \mathrm{O}_{4}$ & $301 / 286$ & 347.2206 & $301 / 219$ & 711.2 \\
\hline
\end{tabular}




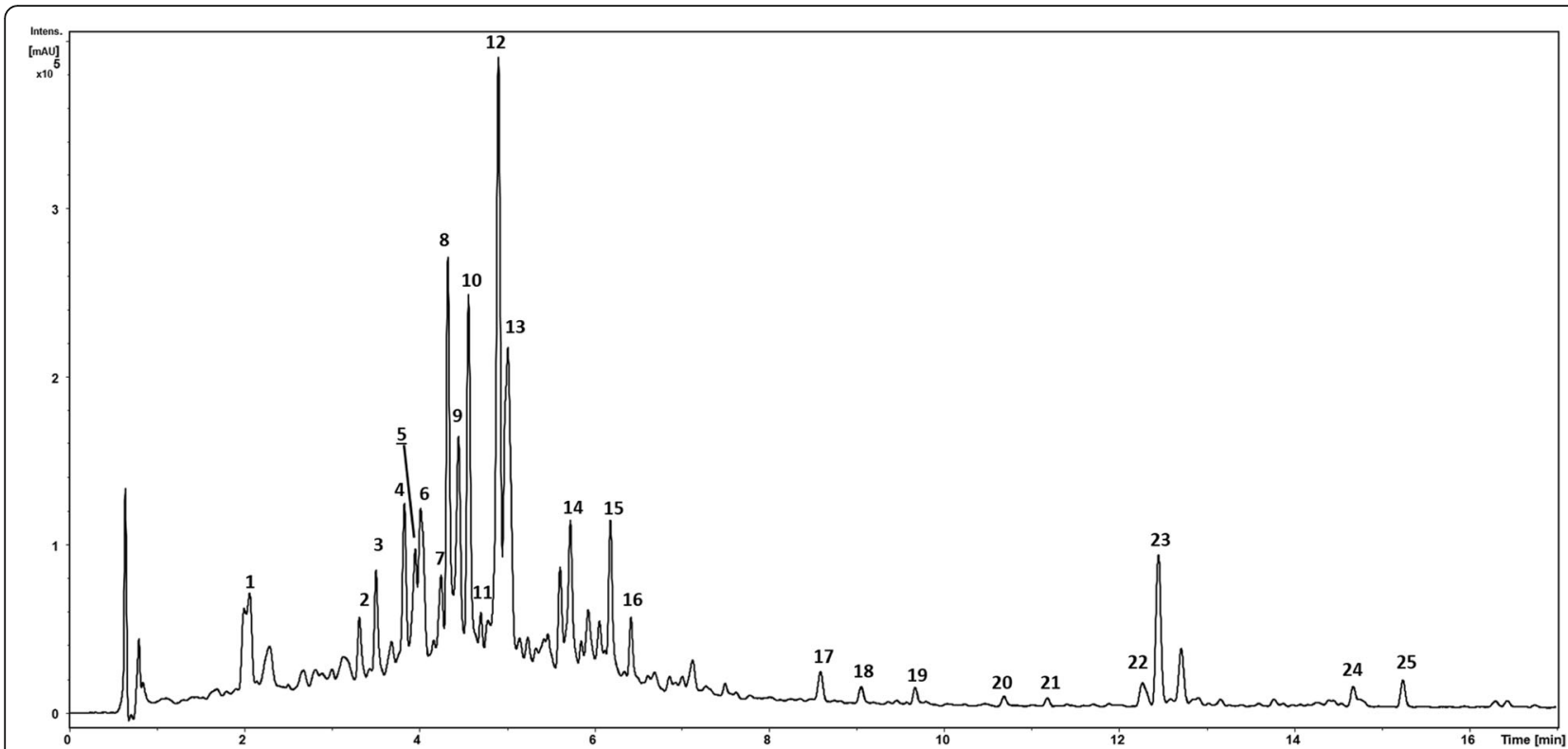

Fig. 1 UV chromatogram at 190-600 nm of a sample of Herbmix at a concentration of $100 \mathrm{mg} / \mathrm{ml}$. Peak numbers represent main compounds listed (No.) in Table 2

after D49. Zn and Hmix+Zn EPGs were significantly lower by D56 $(P<0.05$ and $P<0.01$, respectively). EPGs on D70 were significantly lower in all treated groups compared to $C(P<0.01)$. The results of the necropsy on D70 are shown in Fig. 3. Mean worm counts $70 \mathrm{~d}$ post-infection were significantly lower in Hmix, Zn and Hmix+Zn than in $C(P<0.05$ and $P<0.01)$.

\section{Hematological parameters}

The complete red blood cell (RBC) hemograms of each infected animal identified clinical signs of haemonchosis such as anemia from D35 (Table 4). RBC count, hemoglobin (HGB) level and hematocrit (HCT) were influenced by treatment $(P<0.001)$ and time $(P<0.001)$. The treatment and time affected white blood cell (WBC) levels $(P<0.05)$, but differential counts were not affected $(P>0.05)$.

\section{Inflammatory response}

Mean SAA concentration ranged from 13.7 to $23.7 \mu \mathrm{g} /$ $\mathrm{mL}$ (Table 5). Effect of treatment and the interaction of treatment and time were observed among the groups and sampling days $(P<0.05)$. Mean serum calprotectin concentration ranged from 41.9 to $50.0 \mathrm{ng} / \mathrm{mL}$. Calprotectin concentrations were not influenced by treatment, time and treatment $\times$ time $(P>0.05)$. Serum IgA levels were influenced by treatment $(P<0.01)$.

\section{Antioxidant status}

The treatment influenced MDA $(P<0.05)$ and $\mathrm{SH}$ groups $(P<0.01)$ of lambs (Table 6).

All antioxidant indices, i.e. GPx activity $(P<0.001)$, MDA concentration $(P<0.01)$, TAC $(P<0.001)$ and serum SH levels $(P<0.001)$, were influenced by time.

Table 3 Body weight and mean live-weight gain of lambs infected with $H$. contortus in the experimental groups

\begin{tabular}{|c|c|c|c|c|c|c|c|c|c|}
\hline \multirow[t]{2}{*}{ Parameter } & \multirow[t]{2}{*}{ Day } & \multirow[t]{2}{*}{ C } & \multirow[t]{2}{*}{ Hmix } & \multirow[t]{2}{*}{$\mathrm{Zn}$} & \multirow[t]{2}{*}{$\mathrm{Hmix}+\mathrm{Zn}$} & \multirow[t]{2}{*}{ SD } & \multicolumn{3}{|c|}{ Significance of effects } \\
\hline & & & & & & & Treatment & Time & Treatment $\times$ time \\
\hline BW & 7 & 14.8 & 14.8 & 14.8 & 15.4 & 1.72 & NS & $*$ & NS \\
\hline \multirow[t]{3}{*}{ (kg) } & 35 & 17.9 & 18.1 & 18.6 & 19.2 & 1.87 & & & \\
\hline & 49 & 19.4 & 20.0 & 20.9 & 20.7 & 1.95 & & & \\
\hline & 70 & 22.3 & 22.8 & 24.1 & 23.4 & 2.0 & & & \\
\hline LWG & 35 & 3.15 & 3.28 & 3.82 & 3.78 & 1.01 & NS & $*$ & NS \\
\hline \multirow[t]{2}{*}{ (kg) } & 49 & 1.50 & 1.93 & 2.32 & 1.55 & 0.53 & & & \\
\hline & 70 & 2.92 & 2.72 & 3.20 & 2.68 & 0.67 & & & \\
\hline
\end{tabular}




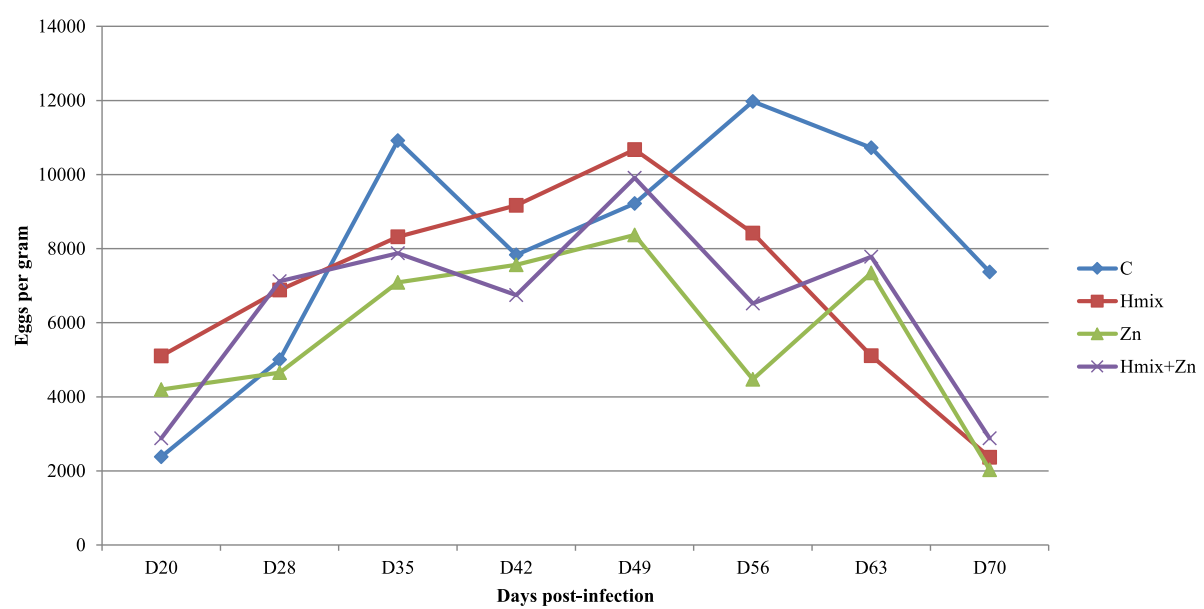

Fig. 2 Mean fecal egg counts of the groups of lambs infected with Haemonchus contortus

\section{Mineral status}

The serum concentrations of zinc $(P<0.001)$, iron $(P<0.01)$ and copper $(P<0.001)$ were influenced by time (Table 7$)$. An interaction of treatment $\times$ time was identified for the zinc concentration $(P<0.001)$.

\section{Discussion}

\section{Bioactive compounds}

Tannin-rich herbs have direct antiparasitic activity against internal nematodes in ruminants and can indirectly increase host resistance $[9,10]$. Traditional medicines made from medicinal plants represent a source of multitarget therapeutics, and their bioactive compounds work synergistically [7, 27]. The UHRMS analysis of the bioactive compounds in Herbmix identified mainly flavonoids (54\%) diterpenes (27\%) and phenolic acids (19\%) (Table 2). Flavonoids can mitigate diseases associated with oxidative stress by their antioxidant properties $[7,28]$ and also probably act via a mechanism similar to that of tannins [29]. Quercetin [28, 30], verbascoside

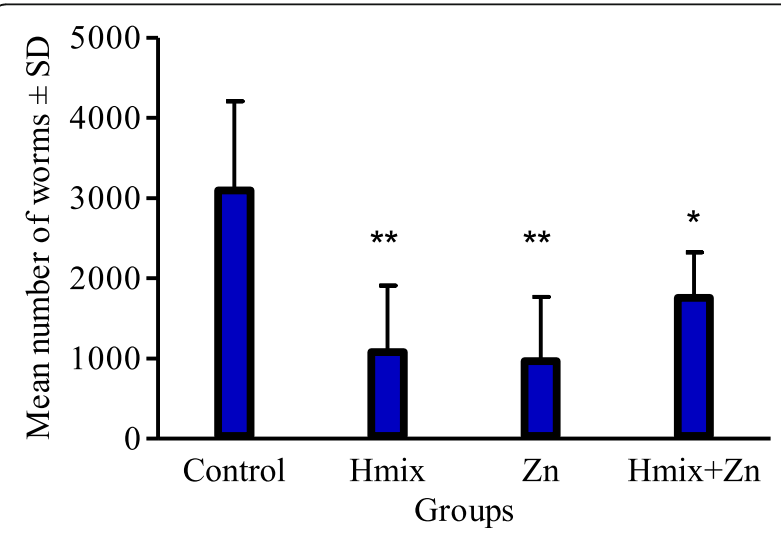

Fig. 3 Abomasal worm counts of Haemonchus contortus in the lambs of each treatment at the end of the experiment
[31, 32] and luteolin [33] were the most abundant Herbmix flavonoids with antioxidant and anti-inflammatory properties. Luteolin and quercetin can inhibit the motility of Trichostrongylus colubriformis larvae [34] and larval exsheathment in $H$. contortus [35]. These flavonoids, however, also synergistically increase the activity of condensed tannins [35]. Carnosic acid and carnosol, which are typical for rosemary, were highly abundant diterpenes in Herbmix, and both have antioxidant activity [36]. Rosmarinic acid, however, was the most bioactive substance in Herbmix. The two phenolic acids in Herbmix, rosmarinic acid [37, 38] and chlorogenic acid [39-41], both have anti-inflammatory and antioxidant biological activities with beneficial health-promoting effects.

\section{Parasitological status}

The effect of Herbmix on BW and LWG in the infected lambs previously observed by Váradyová et al. [42] was not confirmed in the present experiment. Many studies have confirmed the negative impact of gastrointestinal nematode infections on sheep performance. The results of a meta-analysis indicated that weight gain in animals infected with $H$. contortus was $77 \%$ of the gain in parasite-free animals [43]. Most of the trials in the metaanalysis reported a negative effect of parasitism on production, but the effect was significant in only $58.3 \%$ of the trials. EPGs in the treated groups in our study decreased significantly only toward the end of the experiment, after D56. Obtaining significant LWGs in the treated groups in last 14 days of experiment was thus not surprising.

Egg output began to decrease in all three treated groups after D49, with reductions $>70 \%$ between D49 and D70. Two conclusions can be drawn. Firstly, no treatment effect has been documented, because egg output did not change until D49. This is in contrast with 
Table 4 Hematological parameters of lambs infected with $H$. contortus in the experimental groups

\begin{tabular}{|c|c|c|c|c|c|c|c|c|c|}
\hline \multirow[t]{2}{*}{ Parameter } & \multirow[t]{2}{*}{ Day } & \multirow[t]{2}{*}{ C } & \multirow[t]{2}{*}{ Hmix } & \multirow[t]{2}{*}{$\mathrm{Zn}$} & \multirow[t]{2}{*}{$\mathrm{Hmix}+\mathrm{Zn}$} & \multirow[t]{2}{*}{ SD } & \multicolumn{3}{|c|}{ Significance of effects } \\
\hline & & & & & & & Treatment & Time & Treatment $\times$ time \\
\hline $\mathrm{RBC}$ & 7 & 9.89 & 11.0 & 10.8 & 10.3 & 0.992 & $* * *$ & $* * *$ & NS \\
\hline \multirow[t]{3}{*}{$(\mathrm{T} / \mathrm{L})$} & 35 & 5.94 & 6.34 & 6.98 & 6.31 & 0.766 & & & \\
\hline & 49 & 6.23 & 7.14 & 8.07 & 7.21 & 0.725 & & & \\
\hline & 70 & 7.52 & 8.56 & 9.18 & 8.65 & 1.101 & & & \\
\hline HGB & 7 & 97.1 & 103.0 & 97.4 & 97.8 & 11.13 & $* * *$ & $* * *$ & NS \\
\hline \multirow[t]{3}{*}{$(g / L)$} & 35 & 58.0 & 64.6 & 72.3 & 61.8 & 10.40 & & & \\
\hline & 49 & 58.2 & 76.8 & 80.2 & 69.2 & 8.09 & & & \\
\hline & 70 & 72.0 & 87.1 & 90.0 & 81.8 & 9.981 & & & \\
\hline $\mathrm{HCT}$ & 7 & 0.213 & 0.220 & 0.225 & 0.224 & 0.017 & $* * *$ & $* * *$ & NS \\
\hline \multirow[t]{3}{*}{$(L / L)$} & 35 & 0.141 & 0.161 & 0.182 & 0.157 & 0.022 & & & \\
\hline & 49 & 0.138 & 0.186 & 0.195 & 0.172 & 0.019 & & & \\
\hline & 70 & 0.168 & 0.206 & 0.207 & 0.199 & 0.019 & & & \\
\hline WBC & 7 & 8.3 & 10.2 & 7.2 & 8.1 & 3.36 & $*$ & NS & NS \\
\hline \multirow[t]{3}{*}{$(g / L)$} & 35 & 6.1 & 9.9 & 6.9 & 8.7 & 2.40 & & & \\
\hline & 49 & 7.2 & 8.4 & 5.9 & 6.6 & 1.89 & & & \\
\hline & 70 & 7.1 & 7.5 & 6.7 & 7.4 & 1.97 & & & \\
\hline LYM & 7 & 2.0 & 2.6 & 2.1 & 2.8 & 1.24 & NS & NS & NS \\
\hline \multirow[t]{3}{*}{$(g / L)$} & 35 & 2.0 & 3.5 & 1.4 & 2.3 & 1.23 & & & \\
\hline & 49 & 2.3 & 3.1 & 2.3 & 1.8 & 1.13 & & & \\
\hline & 70 & 2.3 & 2.7 & 3.1 & 2.7 & 1.23 & & & \\
\hline MON & 7 & 2.4 & 2.2 & 1.6 & 2.5 & 0.76 & NS & NS & NS \\
\hline \multirow[t]{3}{*}{$(g / L)$} & 35 & 1.8 & 1.9 & 2.5 & 1.9 & 0.74 & & & \\
\hline & 49 & 1.9 & 1.7 & 1.8 & 2.1 & 0.70 & & & \\
\hline & 70 & 2.0 & 1.9 & 1.6 & 1.8 & 0.62 & & & \\
\hline EOS & 7 & 0.224 & 0.092 & 0.036 & 0.183 & 0.2185 & NS & NS & NS \\
\hline \multirow[t]{3}{*}{$(g / L)$} & 35 & 0.101 & 0.034 & 0.141 & 0.048 & 0.1075 & & & \\
\hline & 49 & 0.085 & 0.069 & 0.072 & 0.076 & 0.0378 & & & \\
\hline & 70 & 0.297 & 0.117 & 0.178 & 0.165 & 0.1937 & & & \\
\hline BAS & 7 & 0.400 & 0.576 & 0.377 & 0.293 & 0.3002 & NS & NS & NS \\
\hline \multirow[t]{3}{*}{$(\mathrm{g} / \mathrm{L})$} & 35 & 0.347 & 0.334 & 0.482 & 0.328 & 0.1963 & & & \\
\hline & 49 & 0.290 & 0.380 & 0.270 & 0.343 & 0.2675 & & & \\
\hline & 70 & 0.399 & 0.395 & 0.290 & 0.267 & 0.2675 & & & \\
\hline
\end{tabular}

C control, Hmix Herbmix, Zn Zn-glycinate, Hmix + Zn Herbmix and Zn-glycinate, RBC red blood cells, HGB hemoglobin, HCT hematocrit, $W B C$ total leukocytes, $L Y M$ lymphocytes, MON monocytes, EOS eosinophils, BAS basophils, NS not significant

* $P<0.05$, ** $P<0.01$, *** $P<0.001$

our previous results obtained by Váradyová et al. [42] where egg output decreased by D35. However, Herbmix they used contained more medicinal herbs including also Artemisia absinthium and the anthelmintic activity of Artemisia species against the ovine nematodes has well been documented [44-46]. Secondly, animals increased their resistance to the worms and expelled adult parasites during the course of infection, supported by the significant reductions of parasites in the treated groups at necropsy. Significant effect of treatment on serum IgA levels pointed out on second conclusion that local antibody response may play important role to immunity of lambs to $H$. contortus infection.

\section{Hematological parameters}

The experimental infection of the four groups of lambs with $H$. contortus caused clinical signs of haemonchosis such as anemia as was described by Bordoloi et al. [47]. RBC and HGB were lower for all four infected groups than the normal ranges of 9.00-15.0 T/L and 90.0- 
Table 5 Inflammatory response in lambs infected with $\mathrm{H}$. contortus in the experimental groups

\begin{tabular}{|c|c|c|c|c|c|c|c|c|c|}
\hline \multirow[t]{2}{*}{ Parameter } & \multirow[t]{2}{*}{ Day } & \multirow[t]{2}{*}{ C } & \multirow[t]{2}{*}{ Hmix } & \multirow[t]{2}{*}{$\mathrm{Zn}$} & \multirow[t]{2}{*}{$\mathrm{Hmix}+\mathrm{Zn}$} & \multirow[t]{2}{*}{ SD } & \multicolumn{3}{|c|}{ Significance of effects } \\
\hline & & & & & & & Treatment & Time & Treatment $\times$ time \\
\hline SAA & 7 & 13.7 & 18.8 & 17.6 & 20.7 & 5.10 & * & NS & * \\
\hline \multirow[t]{2}{*}{$(\mu \mathrm{g} / \mathrm{mL})$} & 35 & 17.9 & 15.4 & 23.7 & 14.2 & 5.20 & & & \\
\hline & 49 & 17.9 & 16.9 & 22.9 & 18.6 & 4.12 & & & \\
\hline Calpro & 7 & 49.1 & 49.1 & 48.5 & 44.7 & 4.70 & NS & NS & NS \\
\hline \multirow[t]{2}{*}{$(\mathrm{ng} / \mathrm{mL})$} & 35 & 46.9 & 38.5 & 50.0 & 49.0 & 9.93 & & & \\
\hline & 49 & 41.9 & 42.4 & 48.3 & 45.9 & 10.86 & & & \\
\hline $\lg A$ & 7 & 0.287 & 0.234 & 0.328 & 0.211 & 0.0642 & $* *$ & NS & NS \\
\hline \multirow[t]{3}{*}{$(\mathrm{mg} / \mathrm{mL})$} & 35 & 0.309 & 0.298 & 0.369 & 0.309 & 0.0572 & & & \\
\hline & 49 & 0.224 & 0.315 & 0.360 & 0.204 & 0.0842 & & & \\
\hline & 70 & 0.289 & 0.318 & 0.415 & 0.313 & 0.1124 & & & \\
\hline
\end{tabular}

C control, Hmix Herbmix, Zn Zn-glycinate, Hmix + Zn Herbmix and Zn-glycinate, NS not significant, SAA serum amyloid A, Calpro calprotectin, IgA immunoglobulin A $* P<0.05$

$150.0 \mathrm{~g} / \mathrm{L}$, respectively [48]. HGB was higher in Hmix and $\mathrm{Zn}$ than $\mathrm{C}$. Increased levels of HGB in goats fed a tannin-rich plant mixture containing condensed tannins (1.96\%) were described by Jan et al. [49].

\section{Inflammatory response}

The concentrations of SAA, serum calprotectin and IgA were evaluated as markers of inflammation to monitor $H$. contortus infection. SAA is a non-specific inflammatory protein indicating inflammatory disease, injury or infection but is a highly sensitive, effective marker of inflammation in ruminants [50-52]. The effects of gastrointestinal nematodes on SAA concentration have not been extensively studied, but Ulutaş et al. [53] reported an increase in SAA concentrations with mixed gastrointestinal infections of nematodes and liver trematodes. The concentration of SAA in our study was influenced, however no effects were observed in our previous study of lambs infected with $H$. contortus [42]. The response of SAA to the experimental conditions was weak and non-uniform, so we cannot currently consider SAA a useful marker for monitoring $H$. contortus infections in

Table 6 Antioxidant status in lambs infected with $H$. contortus in the experimental groups

\begin{tabular}{|c|c|c|c|c|c|c|c|c|c|}
\hline \multirow[t]{2}{*}{ Parameter } & \multirow[t]{2}{*}{ Day } & \multirow[t]{2}{*}{ C } & \multirow[t]{2}{*}{ Hmix } & \multirow[t]{2}{*}{$\mathrm{Zn}$} & \multirow[t]{2}{*}{$\mathrm{Hmix}+\mathrm{Zn}$} & \multirow[t]{2}{*}{ SD } & \multirow[b]{2}{*}{ Treatment } & \multirow[b]{2}{*}{ Time } & \multirow[b]{2}{*}{ Treatment $\times$ time } \\
\hline & & & & & & & & & \\
\hline GPx & 7 & 41.2 & 50.8 & 45.4 & 44.2 & 13.21 & NS & $* * *$ & NS \\
\hline \multirow[t]{3}{*}{$(\mathrm{U} / \mathrm{mL})$} & 35 & 20.3 & 23.4 & 29.3 & 24.7 & 8.59 & & & \\
\hline & 49 & 25.9 & 25.4 & 34.7 & 21.6 & 6.07 & & & \\
\hline & 70 & 28.1 & 40.1 & 42.8 & 30.4 & 8.20 & & & \\
\hline MDA & 7 & 0.234 & 0.214 & 0.209 & 0.196 & 0.063 & * & ** & NS \\
\hline \multirow[t]{3}{*}{$(\mu \mathrm{mol} / \mathrm{L})$} & 35 & 0.225 & 0.225 & 0.214 & 0.188 & 0.046 & & & \\
\hline & 49 & 0.259 & 0.248 & 0.271 & 0.267 & 0.049 & & & \\
\hline & 70 & 0.299 & 0.195 & 0.190 & 0.217 & 0.060 & & & \\
\hline TAC & 7 & 0.292 & 0.254 & 0.276 & 0.258 & 0.042 & NS & $* * *$ & NS \\
\hline \multirow[t]{3}{*}{$(\mathrm{mmol} / \mathrm{L})$} & 35 & 0.292 & 0.290 & 0.262 & 0.288 & 0.029 & & & \\
\hline & 49 & 0.319 & 0.318 & 0.309 & 0.338 & 0.025 & & & \\
\hline & 70 & 0.337 & 0.340 & 0.333 & 0.347 & 0.029 & & & \\
\hline SH groups & 7 & 0.291 & 0.287 & 0.299 & 0.296 & 0.030 & $* *$ & $* * *$ & NS \\
\hline \multirow[t]{3}{*}{$(\mathrm{mmol} / \mathrm{L})$} & 35 & 0.329 & 0.369 & 0.352 & 0.344 & 0.034 & & & \\
\hline & 49 & 0.316 & 0.333 & 0.390 & 0.332 & 0.037 & & & \\
\hline & 70 & 0.326 & 0.347 & 0.388 & 0.368 & 0.050 & & & \\
\hline
\end{tabular}

C control, Hmix Herbmix, Zn Zn-glycinate, Hmix + Zn Herbmix and Zn-glycinate, GPx blood glutathione peroxidase, MDA serum malondialdehyde, TAC total antioxidant capacity, $S H$ sulfhydryl, NS not significant

${ }^{*} P<0.05,{ }^{* *} P<0.01,{ }^{* * *} P<0.001$ 
Table 7 Mineral status of serum zinc, iron and copper concentrations (mg/L) in lambs infected with $H$. contortus in the experimental groups

\begin{tabular}{|c|c|c|c|c|c|c|c|c|c|}
\hline \multirow[t]{2}{*}{ Element } & \multirow[t]{2}{*}{ Day } & \multirow[t]{2}{*}{ C } & \multirow[t]{2}{*}{ Hmix } & \multirow[t]{2}{*}{$\mathrm{Zn}$} & \multirow[t]{2}{*}{$\mathrm{Hmix}+\mathrm{Zn}$} & \multirow[t]{2}{*}{ SD } & \multicolumn{3}{|c|}{ Significance of effects } \\
\hline & & & & & & & Treatment & Time & Treatment $\times$ time \\
\hline \multirow[t]{4}{*}{ Zinc } & 7 & 0.456 & 0.487 & 0.539 & 0.527 & 0.038 & NS & ** & $* *$ \\
\hline & 35 & 0.727 & 0.651 & 1.004 & 0.759 & 0.153 & & & \\
\hline & 49 & 0.751 & 0.693 & 0.834 & 0.740 & 0.059 & & & \\
\hline & 70 & 0.773 & 0.833 & 0.823 & 0.871 & 0.041 & & & \\
\hline \multirow[t]{4}{*}{ Iron } & 7 & 1.370 & 1.409 & 1.301 & 1.306 & 0.052 & NS & * & NS \\
\hline & 35 & 0.970 & 1.267 & 1.537 & 1.151 & 0.238 & & & \\
\hline & 49 & 0.876 & 1.351 & 1.351 & 1.270 & 0.228 & & & \\
\hline & 70 & 1.284 & 1.827 & 1.773 & 1.744 & 0.251 & & & \\
\hline \multirow[t]{4}{*}{ Copper } & 7 & 0.601 & 0.641 & 0.637 & 0.701 & 0.041 & NS & ** & NS \\
\hline & 35 & 0.764 & 0.787 & 0.943 & 0.861 & 0.081 & & & \\
\hline & 49 & 0.753 & 0.759 & 0.814 & 0.816 & 0.034 & & & \\
\hline & 70 & 0.764 & 0.861 & 0.844 & 0.826 & 0.042 & & & \\
\hline
\end{tabular}

C control, Hmix Herbmix, Zn Zn-glycinate, Hmix + Zn Herbmix and Zn-glycinate, NS not significant ${ }^{*} P<0.01, * * 0.001$

lambs. Calprotectin is a major cytosolic protein of leucocytes, especially neutrophils. Elevated levels of calprotectin are evident in infectious and inflammatory diseases and are often used as a marker of gastrointestinal inflammation [54]. The response of serum calprotectin during $H$. contortus infection and the experimental treatments in our present study was inconsistent with study of Váradyová et al. [42]. Serum IgA in sheep is predominantly derived from the intestine and closely associated with intestinal mucosal immune responses [14]. Cardia et al. [55] reported higher serum IgA levels against L3 in lambs infected with Trichostrongylus colubriformis. Increased levels of IgA in naturally infected sheep have been positively associated with resistance to Teladorsagia circumcincta by suppressing parasite growth; development and fecundity, mediated by IgA activity against L4 larvae [56, 57]. Serum IgA levels in our study were influenced by treatment, however the immune response against $H$. contortus was very similar in all experimental groups.

\section{Antioxidant status}

Several studies have reported that medicinal plants have a wide range of antioxidant capacities and that phenolic compounds are a major contributor to the antioxidant activity of these plants, making them promising sources of natural antioxidants [58]. Herbmix containing predominantly flavonoids (54\%) exhibited antioxidant potential in vivo [7] by reducing the MDA level, indicating a decrease in lipid peroxidation in the serum, and tending to increase GPx activity in the blood of infected lambs. Zinc can exert its antioxidant action by several possible mechanisms, e.g. the protection of protein $\mathrm{SH}$ groups from oxidation. Zinc is also involved in the synthesis of molecules rich in $\mathrm{SH}$ groups, such as reduced glutathione and metallothionein, which play an antioxidative role [59]. The levels of SH groups on D49 and D70 indicated that zinc supplementation improved the protection of various thiols in the infected lambs by increasing serum SH levels. The activity of blood GPx was higher, and lipid peroxidation in the serum was lower, at the end of the experiment in the groups treated with zinc than in the untreated group. Pivoto et al. [60] also demonstrated that zinc could help reduce the oxidative stress caused by $H$. contortus in lambs. Our findings indicate that treatment with organic zinc alone or in combination with herbal nutraceuticals could potentially provide natural antioxidants for minimizing oxidative stress in nematode infected lambs.

\section{Mineral status}

Experimental infection with $H$. contortus can decrease mineral concentrations in the liver or serum of lambs $[42,61]$. Concentration of serum zinc of lambs in our treatments was not influenced. The efficiency of immunological responses against gastrointestinal nematodes depends on the zinc intake of the host, supporting the important role of zinc in the maintenance of the gut epithelial barrier and intestinal immunity [62]. Our unsupplemented control lambs had marginal serum levels of iron, associated with their low blood HGB levels, but supplementation with zinc or Herbmix maintained higher serum zinc and iron levels, providing better conditions for the lambs to cope with this parasitic disease and reduce parasitic burdens.

\section{Conclusion}

This study did not fully confirm a direct anthelmintic impact on the viability of nematodes, but the treatments 
with herbal nutraceuticals, zinc and both diet supplements together likely indirectly contributed to an increase in the resistance of lambs to nematode infections. The bioactive compounds identified in Herbmix have anti-inflammatory and antioxidant biological activities with beneficial health-promoting effects. The Herbmix, organic zinc and combination of Herbmix with organic zinc contributed to reduction of nematode parasitic infection in experimental animals. The use of herbs with bioactive compounds together with some essential trace elements as alternatives to conventional anthelmintics can be useful for economical, effective and sustainable animal production.

\section{Abbreviations \\ ANOVA: analysis of variance; BW: body weight; C: control; Calpro: calprotectin; D: day of sample collection; DM: dry matter; EPG: eggs per gram; GPx: glutathione peroxidase; HCT: hematocrit; HGB: hemoglobin; Hmix: Herbmix; IgA: immunoglobulin A; LWG: live-weight gain; MDA: malondialdehyde; PSM: plant secondary metabolites; RBC: red blood cells; SAA: serum amyloid A; SH: sulfhydryl; SPE: solid-phase extraction; TAC: total antioxidant capacity; UHRMS: ultra-high resolution mass spectrometry}

\section{Acknowledgements}

The authors are grateful to Valéria Venglovská and Renáta Geročová for their assistance with the laboratory analyses and to Peter Jerga and Gabriel Benkovský for technical assistance.

\section{Funding}

This study was supported by funds from the Slovak Research and Development Agency (APW 14-0169 and APV-0667-12).

\section{Availability of data and materials}

The data sets used and/or analyzed are available from the corresponding author on reasonable request.

\section{Authors' contributions}

$\mathrm{ZV}$ and MV conceived and designed the study protocol, performed the trial, performed the statistical analyses, interpreted the data and wrote the manuscript. DM and $\mathrm{MBr}$ helped with the data acquisition and laboratory analysis. MBa and AK were involved in organizing and conducting the experiment, performed the post-mortem examinations and helped with the laboratory analysis. LG, KC, SK, IP and AC reviewed the study protocol, the ethical application dossier, helped with the laboratory analysis and assisted with the interpretation of the data. SS, LP and MK provided analysis of the bioactive compounds in Herbmix. All authors contributed to editing the manuscript. All authors gave their final approval for publication of the study.

\section{Ethics approval}

Animal use and study design were approved by the Ethics Committee of the Institute of Parasitology of the Slovak Academy of Sciences in accordance with the national legislation in Slovakia - Animal Welfare Act No. 23/2009. Permission to collect study samples was granted by participating sheep farmers. The owner of the animals gave verbal consent to carry out of the experiment.

\section{Consent for publication}

Not applicable.

\section{Competing interests}

The authors declare that they have no competing interests.

\section{Publisher's Note}

Springer Nature remains neutral with regard to jurisdictional claims in published maps and institutional affiliations.

\section{Author details}

'Institute of Animal Physiology, Centre of Biosciences, Slovak Academy of Sciences, Šoltésovej 4-6, 04001 Košice, Slovak Republic. ${ }^{2}$ Institute of Parasitology, Slovak Academy of Sciences, Hlinkova 3, 04001 Košice, Slovak Republic. ${ }^{3}$ Department of Animal Nutrition and Feed Management, Poznan University of Life Sciences, Wolynska 33, 60-637 Poznan, Poland. ${ }^{4}$ Department of Biochemistry, Institute of Soil Science and Plant Cultivation, State Research Institute, Czartoryskich 8, 24-100 Pulawy, Poland. ${ }^{5}$ Department of

Pharmaceutical Biology with Botanical Garden of Medicinal Plants, Medical University of Wroclaw, Wroclaw, Poland.

Received: 19 December 2017 Accepted: 1 March 2018

Published online: 09 March 2018

\section{References}

1. Lans C, Turner N, Khan T, Brauer G, Boepple W. Ethnoveterinary medicines used for ruminants in British Columbia, Canada. J Ethnobiol Ethnomed. 2007;3:11.

2. Kresánek J Jr, Kresánek J. Atlas of medicinal plants and berries, fourth ed. Osveta. Slovakia.

3. Mali RG, Mehta AA. A review on anthelmintic plants. Nat Prod Rad. 2008;7: 466-75.

4. Andlauer W, Fürst P. Nutraceuticals: a piece of history, present status and outlook. Food Res Int. 2002;35:171-6.

5. Hoste H, Torres-Acosta JF, Sandoval-Castro CA, Mueller-Harvey I, Sotiraki S, Louvandini H, Thamsborg SM, Terrill TH. Tannin containing legumes as a model for nutraceuticals against digestive parasites in livestock. Vet Parasitol. 2015;212(1-2):5-17.

6. Lavecchia T, Rea G, Antonacci A, Giardi MT. Healthy and adverse effects of plantderived functional metabolites: the need of revealing their content and bioactivity in a complex food matrix. Crit Rev Food Sci Nutr. 2013;53(2):198-213.

7. Spiegler V, Liebau E, Hensel A. Medicinal plant extracts and plant-derived polyphenols with anthelmintic activity against intestinal nematodes. Nat Prod Rep. 2017;34:627-43.

8. Githiori JB, Athanasiadou S, Thamsborg SM. Use of plants in novel approaches for control of gastrointestinal helminths in livestock with emphasis on small ruminants. Vet Parasitol. 2006;139:308-20.

9. Hoste H, Jackson F, Athanasiadou S, Thamsborg SM, Hoskin SO. The effects of tannin-rich plants on parasitic nematodes in ruminants. Trends Parasitol. 2006;22:253-61.

10. Hoste H, Manolaraki F, Brunet S, Arroyo López C, Martínez-Ortiz de Montellano C, Sotiraki S, Torres Acosta F. The anthelmintic properties of tannin-rich legume forages: from knowledge to exploitation in farm conditions. In: Ranilla MJ, Carro MD, Ben Salem H, Morand-Fehr P, editors. Challenging strategies to promote the sheep and goat sector in the current global context. Zaragoza: CIHEAM/ CSIC/un iversidad de León/FAO; 2011. p. 295-304.

11. Viegi L, Pieroni A, Guarrera PM, Vangelisti R. A review of plants used in folk veterinary medicine in Italy as basis for a databank. J Ethnopharmacol. 2003; 89:221-44.

12. Atanasov AG, Waltenberger $B$, Pferschy-Wenzig EM, Linder T, Wawrosch $C$, Uhrin P, Temml V, Wang L, Schwaiger S, Heiss EH, Rollinger JM, Schuster D, Breuss JM, Bochkov V, Mihovilovic MD, Kopp B, Bauer R, Dirsch VM, Stuppner H. Discovery and resupply of pharmacologically active plant-derived natural products: a review. Biotechnol Adv. 2015;33(8):1582-614.

13. Villalba JJ, Miller J, Ungar ED, Landau SY, Glendinning J. Ruminant selfmedication against gastrointestinal nematodes: evidence, mechanism, and origins. Parasite. 2014;21:31.

14. McRae KM, Stear MJ, Good B, Keane OM. The host immune response to gastrointestinal nematode infection in sheep. Parasite Immunol. 2015;37(12): 605-13.

15. Machado V, Da Silva AS, Schafer AS, Aires AR, Tonin AA, Oliveira CB, Hermes CL, Almeida TC, Moresco RN, Stefani LM, Lopes ST, Mendes RE, Schwertz Cl, Leal ML. Relationship between oxidative stress and pathological findings in abomasum of infected lambs by Haemonchus contortus. Pathol Res Pract. 2014;210:812-7.

16. Fraker PJ, King LE, Laakko T, Vollmer TL. The dynamic link between the integrity of the immune system and zinc status. J Nutr. 2000;130(5S Suppl): 13995-406S.

17. Hughes $S$, Kelly P. Interaction of malnutrition and immune impairment, with specific reference to immunity against parasites. Parasite Immunol. 2006;28: 577-88. 
18. The European Commission, Commission Implementing Regulation (EU) 2016/1095. OJEU. 2016:L182/7-L182/27.

19. Association of Official Analytical Chemists. Official methods of analysis. 15th ed. Arlington: AOAC; 1990.

20. Van Soest PJ, Robertson JB, Lewis BA. Methods for dietary fiber neutral detergent fiber, and non-starch polysaccharides in relation to animal nutrition. J Dairy Sci. 1991;74:3583-97.

21. Coles GC, Bauer C, Borgsteede FHM, Geerts S, Klei TR, Taylor MA, Waller PJ. World Association for the Advancement of veterinary parasitology (W.A.A.V. P) methods for the detection of anthelmintic resistance in nematodes of veterinary importance. Vet Parasitol. 1992:44:35-44.

22. Benzie IFF, Strain JJ. The ferric reducing ability of plasma (FRAP) as a measure of "antioxidant power": the FRAP assay. Anal Biochem. 1996;239:70-6.

23. Paglia DE, Valentine WN. Studies on the quantitative and qualitative characterization of erythrocyte glutathione peroxidase. J Lab Clin Med. 1967; 70:158-69.

24. Jo C, Ahn DU. Fluorometric analysis of 2-thiobarbituric acid reactive substances in Turkey. Poultry Sci. 1998;77:475-80.

25. Ellman GL. Tissue sulfhydryl groups. Arch Biochem Biophys. 1959;82:70-7.

26. Grešáková L, Venglovská K, Čobanová K. Dietary manganese source does not affect $\mathrm{Mn}, \mathrm{Zn}$ and $\mathrm{cu}$ tissue deposition and the activity of manganesecontaining enzymes in lambs. J Trace Elem Med Biol. 2016;38:138-43.

27. Brusotti G, Cesari I, Dentamaro A, Caccialanza G, Massolini G. Isolation and characterization of bioactive compounds from plant resources: the role of analysis in the ethnopharmacological approach. J Pharm Biomed Anal. 2014; 87:218-28.

28. David AVD, Arulmoli R, Parasuraman S. Overviews of biological importance of quercetin: a bioactive flavonoid. Pharmacogn Rev. 2016;10(20):84-9.

29. Barrau E, Fabre N, Fouraste I, Hoste H. Effect of bioactive compounds from sainfoin (Onobrychis viciifolia Scop.) on the in vitro larval migration of Haemonchus contortus: role of tannins and flavonol glycosides. Parasitology. 2005:131:531-8

30. Sultana B, Anwar F. Flavonols (Kaempeferol, quercetin, myricetin) contents of selected fruits, vegetables and medicinal plants. Food Chem. 2008;108: 879-84

31. Pardo F, Perich F, Villarroel $L$, Torres $R$. Isolation of verbascoside, an antimicrobial constituent of Buddleja globosa leaves. J Ethnopharmacol. 1993;39(3):221-2.

32. Speranza L, Franceschelli S, Pesce M, Menghini L, Patruno A, Vinciguerra I, De Lutiis MA, Felaco M, Felaco P, Grilli A. Anti-inflammatory properties of the plant Verbascum mallophorum. J Biol Regul Homeost Agents. 2009;23(3): 189-95.

33. Seelinger G, Merfort I, Schempp CM. Anti-oxidant, anti-inflammatory and anti-allergic activities of luteolin. Planta Med. 2008;74:1667-77.

34. Kozan E, Anul SA, Tatli II. In vitro anthelmintic effect of Vicia pannonica var. purpurascens on trichostrongylosis in sheep. Exp Parasitol. 2013;134:299-303.

35. Klongsiriwet C, Quijada J, Williams AR, Mueller-Harvey I, Williamson EM, Hoste H. Synergistic inhibition of Haemonchus contortus exsheathment by flavonoid monomers and condensed tannins. Int J Parasitol Drugs Drug Resist. 2015;5:127-34.

36. Loussouarn M, Krieger-Liszkay A, Svilar L, Bily A, Birtić S, Havaux M. Carnosic acid and carnosol, two major antioxidants of rosemary, act through different mechanisms. Plant Physiol. 2017;175(3):1381-94.

37. Petersen M, Simmonds MS. Rosmarinic acid. Phytochemistry. 2003;62(2):121-5.

38. Borrás-Linares I, Stojanović Z, Quirantes-Piné R, Arráez-Román D, Švarc-Gajić J, Fernández-Gutiérrez A, Segura-Carretero A. Rosmarinus officinalis leaves as a natural source of bioactive compounds. Int J Mol Sci. 2014;15(11):20585-606.

39. Clifford MN. Chlorogenic acids and other cinnamates - nature, occurrence, dietary burden, absorption and metabolism. J Sci Food Agric. 2000;80(7): 1033-43.

40. Sato Y, Itagaki S, Kurokawa T, Ogura J, Kobayashi M, Hirano T, Sugawara M, Iseki K. In vitro and in vivo antioxidant properties of chlorogenic acid and caffeic acid. Int J Pharm. 2011;403(1):136-8.

41. Tajik N, Tajik M, Mack I, Enck P. The potential effects of chlorogenic acid, the main phenolic components in coffee, on health: a comprehensive review of the literature. Eur J Nutr. 2017; https://doi.org/10.1007/s00394-017-1379-1.

42. Váradyová Z, Kišidayová S, Čobanová K, Grešáková L’, Babják M, Königová A, Urda Dolinská M, Várady M. The impact of a mixture of medicinal herbs on ruminal fermentation, parasitological status and hematological parameters of the lambs experimentally infected with Haemonchus contortus. Small Rum Res. 2017;151:124-32.
43. Mavrot F, Hertzberg H, Torgerson P. Effect of gastro-intestinal nematode infection on sheep performance: a systematic review and meta-analysis. Parasit Vectors. 2015;8:557.

44. Iqbal Z, Lateef M, Ashraf M, Jabbar A. Anthelmintic activity of Artemisia brevifolia in sheep. J Ethnopharmacol. 2004;93:265-8.

45. Tariq KA, Chishti MZ, Ahmad F, Shawl AS. Anthelmintic activity of extracts of Artemisia absinthium against ovine nematodes. Vet Parasitol. 2009;160:83-8.

46. Irum S, Ahmed H, Mirza B, Donskow-Łysoniewska K, Muhammad A, Qayyum $M$, Simsek S. In vitro and in vivo anthelmintic activity of extracts from Artemisia parviflora and A. sieversiana. Helminthologia. 2017;54:218-24.

47. Bordoloi G, Jas R, Ghosh JD. Changes in the haemato-biochemical pattern due to experimentally induced haemonchosis in Sahabadi sheep. J Parasit Dis. 2012;36:101-5.

48. Jackson PGG, Cockcroft PD. Laboratory reference values: Haematology. In Clinical Examination of Farm Animals. Copyright @ 2002; Blackwell Science Ltd.

49. Jan $O Q$, Kamili N, Ashraf A, lqbal A, Sharma RK, Rastogi A. Haematobiochemical parameters of goats fed tannin rich Psidium guajava and Carissa spinarum against Haemonchus contortus infection in India. J Parasit Dis. 2015;39(1):41-8.

50. Karreman HJ, Wentink GH, Wensing T. Using serum amyloid a to screen dairy cows for sub-clinical inflammation. Vet Q. 2000;22:175-8.

51. Petersen $\mathrm{HH}$, Nielsen JP, Heegaard PMH. Application of acute phase protein measurements in veterinary clinical chemistry. Vet Res. 2004;35:163-87.

52. Eckersall PD, Bell R. Acute phase proteins: biomarkers of infection and inflammation in veterinary medicine. Vet J. 2010;185:23-7.

53. Ulutaş PA, Voyvoda H, Ulutaş B, Aypak S. Haptoglobin, serum amyloid-A and ceruloplasmin concentrations in goats with mixed helminth infection. Turkiye Parazitol Derg. 2008;32:229-33.

54. Herrera OR, Christensen ML, Helms RA. Calprotectin: clinical applications in pediatrics. J Pediatr Pharmacol Ther. 2016;21:308-21.

55. Cardia DF, Rocha-Oliveira RA, Tsunemi MH, Amarante AF. Immune response and performance of growing Santa Ines lambs to artificial Trichostrongylus colubriformis infections. Vet Parasitol. 2011;182(2-4):248-58.

56. Stear MJ, Bairden K, Innocent GT, Mitchell S, Strain S, Bishop SC. The relationship between $\lg A$ activity against 4th-stage larvae and densitydependent effects on the number of 4th-stage larvae of Teladorsagia circumcincta in naturally infected sheep. Parasitology. 2004;129:363-9.

57. Halliday AM, Routledge CM, Smith SK, Matthews JB, Smith WD. Parasite loss and inhibited development of Teladorsagia circumcincta in relation to the kinetics of the local IgA response in sheep. Parasite Immunol. 2007;29(8): 425-34.

58. Singh A, Singh S, Prasad SM. Role of medicinal plants for health perspective: special references to antioxidant potential. J Chem Biol Ther. 2016;1:106. https://doi.org/10.4172/2572-0406.1000106.

59. Marreiro DN, Cruz KJC, Morais JB, Besserra JB, Severo JS, de Oliveira AR. Zinc and oxidative stress: current mechanisms. Antioxidants (Basel). 2017;6:E24. https://doi.org/10.3390/antiox6020024.

60. Pivoto FL, Torbitz VD, Aires AR, da Rocha JF, Severo MM, Grando TH, Peiter M, Moresco RN, da Rocha JB, Leal ML. Oxidative stress by Haemonchus contortus in lambs: influence of treatment with zinc edetate. Res Vet Sci. 2015;102:22-4.

61. Schafer AS, Leal MLR, Molento MB, Aires AR, Duarte MMMF, Carvalho FB, Tonin AA, Schmidt L, Flores EMM, Franca RT, Grando TH, Minho A, Krause A, Antoniazzi AQ, Lopes STA. Immune response of lambs experimentally infected with Haemonchus contortus and parenterally treated with a combination of zinc and copper. Small Rumin Res. 2015;123:183-8.

62. Scott ME, Koski KG. Zinc deficiency impairs immune responses against parasitic nematode infections at intestinal and systemic sites. J Nutr. 2000; 130:1412S-20S. 